\title{
Gambaran Work-life Balance Pada Prajurit Wanita Yang Berperan Ganda Di Dinas X TNI-AL Surabaya
}

\author{
Gathot Himmawan \\ Jurusan Psikologi, Fakultas Psikologi, Universitas Airlangga \\ Jalan Airlangga 4-6 Surabaya \\ gathot.himmawan-2016@psikologi.unair.ac.id
}

Infromasi Artikel

\begin{tabular}{ll}
\hline Tanggal masuk & $16-02-2020$ \\
Tanggal revisi & $09-06-2020$ \\
Tanggal diterima & $09-06-2020$
\end{tabular}

Kata Kunci: wanita TNI; peran ganda; work-life balance
Keywords:

gifted;

homeschooling;

parent's role;

school's role;

teacher's role.
Abstrak

Seiring dengan perkembangan jaman yang semakin maju, pergeseran nilai -nilai di masyarakat mengenai perempuan bekerja dicatat mengalami kemajuan yang terus meningkat dari dekade sebelumnya. Salah satu penyebabnya adalah kini wanita telah memperoleh kesempatan pendidikan dan kesempatan pekerjaan yang sama dengan pria sehingga dapat memiliki peran lebih dari satu atau yang disebut peran ganda. Fenomena wanita yang memiliki peran ganda saat ini dapat ditemui pada wanita yang meniti karir di bidang pertahanan negara sebagai prajurit TNI wanita khusus pada TNI Angkatan Laut. Salah satu tuntutan yang harus dimiliki para prajurit TNI adalah kompetensi dan skill atau kinerja yang handal dan optimal. Namun, terkait dengan kodrat diri mereka sebagai wanita Indonesia, para Kowal yang telah berkeluarga tidak dapat memungkiri tugas utama sebagai ibu rumah tangga. Peran ganda mengakibatkan tuntutan lebih yang dapat menimbulkan situasi yang tidak mudah untuk diselesaikan. Prajurit TNI wanita yang berperan ganda juga perlu mencapai keseimbangan antara kehidupan dan pekerjaannya. Keseimbangan antara kehidupan dan pekerjaan ini disebut dengan work-life balance. Dalam penelitian ini menggunakan desain penelitian kualitatif dengan pendekatan berupa studi kasus deskriptif. Pengambilan sampel dalam penelitian kualitatif menggunakan purposive sampling. Teknik penggalian data yang digunakan adalah Teknik wawancara, observasi dan dokumentasi. Berdasarkan hasil penelitian secara keseluruhan, subjek merasa telah seimbang dalam menjalani peran ganda. Namun, disamping itu subjek menyadari bahwa prioritas pekerjaannya adalah resiko yang harus dihadapinya, sehingga konflik-konflik yang muncul terkait pekerjaan dengan keluarganya dapat diatur sedemikian rupa dengan strategi komunikasi.

Abstract

Along with the development of increasingly advanced times, shifts in the values of society regarding working women are noted to have progressed that continues to increase from the previous decade. One reason is that now women have had the same educational and employment opportunities as men so that they can have more than one role or what are called multiple roles. The phenomenon of women who have a dual role today can be found in women who are pursuing careers in the field of national defense as special woman soldiers in the Navy. One of the demands that must be had by TNI soldiers is competence and skill or performance that is reliable and optimal. However, related to the nature of themselves as Indonesian women, they have a family can not deny the main task as a housewife. Multiple roles lead to more demands which can lead to situations that are not easy to resolve. Woman soldiers who play a dual role also need to strike a balance between their lives and work. This balance between life and work is called work-life balance. In this study using a qualitative research design with an approach in the form of descriptive case 
studies. Sampling in qualitative research uses purposive sampling. Data techniques used are interview, observation and documentation. Based on the results of the overall study, subjects felt that they were balanced in undergoing multiple roles. However, besides that the subject realizes that the priority of his work is the risk she must face, so that conflicts that arise related to work with his family can be arranged in such a way as a communication strategy.

\section{PENDAHULUAN}

Seiring dengan perkembangan jaman yang semakin maju, pergeseran nilai-nilai di masyarakat mengenai perempuan bekerja dicatat mengalami kemajuan yang terus meningkat dari dekade sebelumnya. Salah satu penyebabnya adalah kini wanita telah memperoleh kesempatan pendidikan dan kesempatan pekerjaan yang sama dengan pria sehingga dapat memiliki peran lebih dari satu atau yang disebut peran ganda. Peran ganda adalah kondisi di mana seorang wanita selain menjadi istri bagi suaminya dan menjadi ibu bagi anak-anaknya, seorang wanita memiliki pekerjaan di berbagai bidang atau profesi lain (Hermayanti, 2014). Fenomena wanita yang memiliki peran ganda saat ini dapat ditemui pada wanita yang meniti karir di bidang pertahanan negara sebagai prajurit TNI wanita. Khusus pada TNI Angkatan Laut, ditemukan hasil survey yang menjelaskan bahwa terdapat 1.766 wanita yang memilih untuk berkarir di Korps Wanita TNI Angkatan Laut (KOWAL) se-Indonesia yang tidak sedikit di antaranya telah berkeluarga. Data menunjukkan $70 \%$ prajurit TNI wanita angkatan laut Indonesia telah menikah (Data pers TNI AL, 2016). TNI dituntut mampu menghadapi ancaman dan tantangan dengan lebih efektif. Salah satu tuntutan yang harus dimiliki para prajurit TNI adalah kompetensi dan skill atau kinerja yang handal dan optimal. Korps Wanita Angkatan Laut (Kowal) memiliki tugas dan tanggung jawab tidak berbeda dengan personel laki-laki, Kowal juga memiliki beberapa tugas penting di dalam profesinya. Kowal bertugas untuk menjaga kedaulatan dan wilayah Negara Kesatuan Republik Indonesia, termasuk tugas perang dan tugas-tugas lain yang terkait dengan tanggung jawabnya sebagai seorang prajurit. Namun, terkait dengan kodrat diri mereka sebagai wanita Indonesia, para Kowal yang telah berkeluarga tidak dapat memungkiri tugas utama sebagai ibu rumah tangga dan tugas mulia untuk mendidik anak-anaknya para generasi penerus bangsa.

Peran ganda mengakibatkan tuntutan lebih yang dapat menimbulkan situasi yang tidak mudah untuk diselesaikan. Kedua peran menuntut kinerja yang sama baiknya. Salah satu upaya meminimalkan terjadinya konflik antara antara pekerjaan dan keluarga adalah dengan menyeimbangkan antara aktivitas pekerjaan dan aktivitas dalam keluarga. Keseimbangan antara kehidupan dan pekerjaan ini disebut dengan work-life balance. Kaur (2013) mengemukakan bahwa work-life balance memainkan peran penting untuk hidup terbebas dari masalah kesehatan yang berhubungan dengan mental (seperti stress, depresi, kecemasan, dan lain-lain) serta memperoleh kepuasan dalam pekerjaan, dan strategi adaptif dalam menangani situasi stress baik di tempat kerja ataupun di rumah. Tujuan dari penelitian ini yaitu mengetahui bagaimana gambaran work life balance pada prajurit wanita di Dinas Psikologi TNI AL Surabaya.

Fisher (Novelia, 2013), menyatakan work -life balance adalah hal yang dilakukan seseorang dalam membagi waktu baik ditempat kerja dan aktivitas lain diluar kerja yang didalamnya terdapat individual behavior dimana hal ini dapat menjadi sumber konflik pribadi dan menjadi sumber energi bagi diri sendiri. Memiliki empat komponen penting yaitu waktu, perilaku, ketegangan dan energi. Fisher, Bulger, dan Smith (2009) mengatakan jika work-life balance memiliki 4 dimensi pembentuk, yaitu Work Interference with Personal Life (WIPL), Personal Life Interfer- 
ence With Work (PLIW), Personal Life Enhancement Of Work (PLEW), Work Enhancement Of Personal Life. Manfaat dari keseimbangan kehidupan kerja (work-life balance) ini sangat banyak seperti halnya dapat mengurangi kemangkiran (absenteeism) dan keterlambatan (lateness), meningkatkan produktivitas \&organizational image, menambah komitmen dan loyalitas karyawan, meningkatnya retensi dari valuableemployee, mengurangi biaya lembur dan berkurangnya tingkat turnover pekerja. Selain itu juga, dapat meningkatkan kepuasan kerja, keamanan kerja (job security) serta dapat mengurangi tingkat stres kerja dan meningkatkan kesehatan fisik dan mental para pekerjanya.

Dalam hal ini peneliti mencoba melihat gambaran pada Kowal yaitu Prajurit atau personel wanita pada kesatuan tubuh TNI disebut dengan WAN TNI (Brigjen TNI Susi, 2016) yang selanjutnya khusus pada satuan TNI Angkatan Laut disebut dengan Korps Wanita Angkatan Laut (Kowal) yang memiliki peran ganda. Peran ganda adalah dua peran yang dijalankan oleh seorang saja dalam menjalankan suatu tugas yang memang sudah menjadi hal yang dikerjakannya (bekerja) dan juga salah satu peran itu telah menjadi kodrat yang memang telah melekat dari dahulu pada diri dan tanggung jawabnya (ibu rumah tangga) didalam sebuah keluarga (S. R. Parker, R. K. Brown dkk, 1992).

\section{METODE}

Penelitian ini menggunakan desain penelitian kualitatif. Penelitian kualitatif efektif digunakan untuk memperoleh informasi yang spesifik mengenai nilai, opini, perilaku dan konteks sosial menurut keterangan populasi. Pendekatan yang dilakukan berupa studi kasus deskriptif. Yin (2014) mengemukakan bahwa Studi kasus deskriptif merupakan studi yang mengekplorasi suatu masalah dengan batasan dan urutan terperinci, memiliki pengambilan data yang mendalam, dan menyertakan berbagai informasi. Pengambilan sampel dalam penelitian ini menggunakan purposive sampling dengan berbagai pendekatan yang paling representatif untuk penelitian kualitatif.
Dalam penelitian ini yang menjadi subjek penelitian adalah prajurit wanita TNI AL yang berstatus masih bertugas, sudah menikah dan memiliki anak. Pemilihan subjek dalam pengambilan sampel berdasarkan keriteria yang ditentukan peneliti. Teknik penggalian data menggunakan teknik wawancara semi terstruktur dengan tujuan agar subjek (prajurit wanita TNI AL) lebih bebas mengungkapkan pendapatnya mengenai proses work life balance pada dirinya dan apa saja faktor yang mempengaruhinya. Penelitian ini melakukan observasi dengan tujuan menyajikan gambaran realistik proses work life balance pada prajurit TNI AL, untuk membantu mengerti perilaku work life balance-nya, dan untuk evaluasi pengukuran terhadap aspek work life balance. Penelitian ini menggunakan jenis observasi partisipasipasif dan observasi partisipasi-aktif. Pada penelitian ini, peneliti mengambil data di salah satu satuan kerja Dinas Psikologi TNI AL Surabaya. Peneliti menggunakan teknik dokumentasi di tempat subjek bertugas dan sebagai outputnya adalah data hasil penilaian kerja. Selain itu peneliti juga menggunakan data-data seperti foto kegiatan subjek sehariharinnya. Basis data (data base) penelitian ini menggunakan alat perekam dengan menggunakan tape recorder, pencatatan melalui transkrip wawancara, dan hasil observasi juga foto-foto kegiatan penggalian data. Proses wawancara dilakukan sebanyak dua kali pada subjek dengan jadwal yang bersifat fleksibel mengikuti waktu yang diminta oleh subjek. Wawancara juga dilakukan pada significant other dari teman satu profesi subjek yang dilakukan sebanyak satu kali.

\section{HASIL}

Berdasarkan hasil wawancara, Subjek memiliki strategi dalam mengatur kehidupan pribadinya untuk meningkatkan performance kerjanya. Salah satunya seperti mengkomunikasikan pada pasangan segala konsekuensi dan prioritas dari seorang istri yang bekerja sebagai prajurit wanita TNI AL agar nantinya dapat dimengerti, tidak pernah meninggalkan anak sendiri tanpa pendamping meminta bantuan orang lain seperti ibu, atau mertua ketika 
subjek dan suami tidak bisa mengurus anak, mencurahkan $100 \%$ fokus dan perhatiannya kepada salah satu peran yang ia sedang emban dan meninggalkan peran lainnya dulu untuk sementara, menguasai diri dan emosi ketika terjadi masalah dirumah karena menurut subjek itu hanya emosi sesaat, sehingga ia dapat fokus pada pekerjaan, menyampingkan atau mengabaikan seluruh kebutuhan psikologisnya sebagai individu, dan meletakkan kebutuhan keluarga sebagai kebutuhan kedua setelah negara, mengkomunikasikan dan tidak mengambil pikiran suatu masalah terkait diluar kerja, mengkomunikasikan dan mengkoordinasikan, kepada dinas untuk mengambil jalan tengah ketika terjadi konflik kemudian mengikuti segala perintah arahan dari atasan karena dinas atau atasan akan membantu terhadap alternatif solusi, pengambilan keputusan. Penelitian ini didukung oleh beberapa penelitian sebelumnya mengenai work life balance diantaranya menunjukkan hasil bahwa work life balance mempunyai pengaruh yang signifikan terhadap kepuasan kerja (Maslichah,2016). Penelitian lain juga menyebutkan adanya work life balance mempengaruhi kepuasan kerja dengan dimediasi oleh stres kerja (Nurendra, 2016).

Secara keseluruhan, subjek merasa telah seimbang dalam menjalani peran ganda. Subjek merasa keseimbangan antara kehidupan pekerjaan dan keluarganya masih dalam batas normal. Namun, disamping itu subjek menyadari bahwa prioritas pekerjaannya adalah resiko yang harus dihadapinya, sehingga konflik-konflik yang muncul terkait pekerjaan dengan keluarganya dapat diatur sedemikian rupa dengan strategi komunikasi yang efektif.

\section{PEMBAHASAN}

Dalam penelitian ini, peneliti memfokuskan work life balance pada Prajurit TNI AL berjenis kelamin wanita yang berada di Surabaya. Untuk waktu penelitian dilakukan selama kurang lebih 3 bulan, yaitu sejak awal bulan Oktober hingga awal Desember 2016. Tugas yang diemban sebagai prajurit TNI AL terbagi atas beberapa bagian diantaranya tugas struktural dan tugas tambahan. Tugas struktural adalah yang berupa tugas utama atau tugas perintah atasan langsung dan bahkan berupa tugas wajib untuk pengembangan diri prajurit seperti melaksanakan pendidikan lanjut, sedangkan tugas tambahan adalah tugas yang berupa perintah diluar tugas pokok dan kedinasan dari senior.

Di dalam kesatuannya subjek memiliki tugas struktural di bagian pengembangan metodologi, di mana subjek bertugas untuk mengembangkan metode penelitian psikologi dan pengembangan alat serta pembaharuan norma- norma psikologi yang dimiliki oleh TNI AL. Tugas tambahan yang di dapatkan subjek terkadang lebih banyak dibandingkan tugas pokok atau struktural. Kedua tugas tersebut memberikan dampak pada kehidupan pribadi subjek yaitu pada kehidupan subjek bersama keluarga dan anak-anaknya. Dampak yang dihasilkan dari banyaknya tugas dari organisasi TNI memberikan efek diantaranya adanya bentrok ketika keduanya membutuhkan subjek sehingga subjek harus memilih untuk memprioritaskan hal mana yang lebih membutuhkan dirinya. Konflik lain yang terjadi yaitu ketika pasangan subjek memberikan emosi yang negatif kepada subjek seperti marah. Emosi negatif marah yang ditunjukkan pasangan yaitu diam. Dampaknya pada diri subjek adalah mengalami stress yang menyebabkan kondisi tubuh subjek menurun. Menurunnya kondisi tubuh subjek berupa berat badan yang menurun dan kondisi diri penampilan yang tidak terurus.

Penelitian ini menunjukkan perlu adanya keseimbangan dalam bekerja dan juga berkehidupan sosial dimana dalam hal ini seorang wanita memiliki peran ganda yang memposisikan dirinya memiliki kemampuan dalam mengatur segala hal dalam kehidupannya. Subjek peneliti merasa telah seimbang dalam menjalani perannya baik sebgaai anggota TNI AL maupun sebagai ibu rumah tangga. Namun, subjek menyadari bahwa prioritas pekerjaannya merupakan resiko yang harus dihadapinya, sehingga konflik-konflik yang muncul terkait 
pekerjaan dengan keluarganya dapat diatur sedemikian rupa salah satunya menggunakan strategi komunikasi yang efektif.

\section{KESIMPULAN}

Berdasarkan hasil penelitian yang telah dilakukan termasuk analisis data dan pembahasan yang telah dijelaskan sebelumnya, gambaran work-life balance pada prajurit wanita Dinas Psikologi TNI-AL memiliki dimensi-dimensi seperti yang dikemukakan oleh Fisher yaitu sebagai berikut:

1. Tugas sebagai seorang KOWAL (tugas struktural dan berbagai tugas tambahan) memberikan dampak pada kehidupan pribadi subjek. Dampak-dampak pada kehidupan pribadi subjek seperti, berat badan yang menurun, penampilan yang diabaikan, perselisihan dengan pasangan, timbulnya reaksi pada anak yang menyuruh sang ibu berhenti bekerja, berkurangnya interaksi dengan teman-teman, berkurangnya hubungan interpersonal keluarga khususnya dengan anak, serta tertundanya tugas-tugas sebagai ibu rumah tangga, yaitu mencuci, memasak, dan membereskan rumah, bahkan berakibat pada pendelegasian tugas rumah pada asisten rumah tangga.

2. Terdapat permasalahan dalam kehidupan pribadi subjek yang berdampak pada pekerjaannya, yaitu keadaan anak yang kurang sehat. Diketahui bahwa kondisi anak subjek yang sakit membuat tugas pekerjaan subjek tertunda, sehingga terpaksa didelegasikan kepada orang lain untuk sementara sebagai seorang prajurit TNI.

3. Dalam menjalankan peran ganda subjek memiliki strategi mengatur kehidupan pribadi agar dapat meningkatkan kualitas kerjanya, yaitu dengan komunikasi. Subjek mengkomunikasikan berbagai hal dengan suaminya. Hal itu merupakan upaya yang dilakukan agar suami mengetahui apa yang menjadi pekerjaan istri dan jika dimungkinkan memberikan nasehat atau mengingatkan istri untuk menyeimbangkan tugas antara tugas kantor dan tugas rumah. Komunikasi dengan anak juga diperlukan untuk memberikan pengertian agar anak mengerti keadaan ibunya.

4. Strategi mengatur kehidupan kerja agar dapat meningkatkan kualitas kehidupan pribadi, berkoordinasi atau mengkomunikasikan semua kepada atasan mengenai konflik yang ia temui terkait keluarga dan pekerjaan, sehingga solusinya akan lebih mudah.

Berdasarkan hasil penelitian dan kesimpulan yang telah diuraikan di atas, maka terdapat beberapa saran yang diberikan yaitu Para prajurit wanita berperan ganda dapat menggunakan strategi komunikasi serupa dalam menghadapi konflik pada kehidupan pekerjaan dan keluarganya. Kemudian hendaknya para prajurit wanita berperan ganda mampu mempertahankan ketangguhannya dalam mengemban segala tugasnya, baik di kedinasan maupun tugas sebagai istri dan seorang ibu.

\section{DAFTAR PUSTAKA}

Dadang S. Anshori (1997). Membincangkan Feminisme. Bandung: Pustaka Hidayah.

Direnzo, M. S. (2010). An Examination of the Roles of Protean Career Orientation and Career Capital on Work and Life Outcomes. Journal of Philosophy, 1215.

Ermawati. (2016). Peran Ganda Wanita Karier(Konflik Peran Ganda Wanita Karier Ditinjau dalam Prespektif Islam). Jurnal Edutama. Vol. 2(2).

Fisher, G. G., Bulger, C. A., \& Smith, C. S. (2009). Beyond Work and family: A Measure pf Work/Nonwork Interference and Enhancement. Journal Ofoccupational Health Psychology. American Psychological Association.Vol.14(4).

Ganapathi, I. M. (2016) Pengaruh Work-Life Balance terhadap kepuasan kerja karyawan (Studi Pada PT. Bio Farma Persero). Fakultas Ekonomi dan Bisnis 
Universitas Bina Sarana Informatika.

Greenhaus, J. H., Collins, K. M., \& Shaw, J. D. (2003). The Relation Between Work -Family Balance and Quality. Journal of Vocational Behavior, 510-531.

Handayani (2013). Keseimbangan Kerja Keluarga pada Perempuan Bekerja. Jurnal Buletin Psikologi. Vol 21(2) Hal, 90-101.

Handayani, Afiyati, Dan Adiyanti (2015). Studi Eksplorasi Makna Keseimbangan Kerja Keluarga Pada Ibu Bekerja. Seminar Psikologi \& Kemanusiaan :Forum Umm, Isbn: 978979-796-324-8

Hermayanti. (2014). Kebermaknaan Hidup dan Konflik Peran Ganda pada Wanita Karier yang Berkeluarga di Kota Samarinda.Ejournal Psikologi, 2 (3): 269-278.

Iklima. (2014). Peran Wanita Karir dalam Melaksanakan Fungsi Keluarga (Studi Kasus PNS Wanita yang Telah Berkeluarga di Balai Kota Bagian Humas dan Protocol Samarinda. Ejournal Ilmu Sosiatri. Vol 2 No.3.

Indriyani, Azazah. (2009). Pengaruh Konflik Peran Ganda dan Stress Kerja terhadap Kinerja Perawat Wanita Rumah Sakit. Tesis. Semarang: Universitas Diponegoro.

Irwan Abdullah (1997). Sangkan Paran Gender (Pusat Penelitian Kependudukan UGM). Yogyakarta: Pustaka Tama Pelajar.

Isnaeni. A. (2015). Peran Work-Life Balance terhadap Kesehatan Mental dengan Gender Sebagai Moderator pada Perawat di RS X Yogyakarta. Jurnal UIN Sunan Kalijaga Yogyakarta.

Julia Cleves Mosse. (1996).Gender dan Pembangunan. Yogyakarta: Pustaka Pelajar.

J. Dwi Narwoko, Bagong Suyanto (2007). Sosiologi Teks Pengantar Dan Terapan
Jakarta: Kencana.

Kaiser, S., Ringlstetter, M., Reindl, C., \& Stolz, M. (2010). The Impact of Corporate Work-Life Balance Initiatives on Employee Commitment: An Empirical Investigation in The German Consultancy Sector. Zeitschrift für Personal Forschung. 24(3), 231265.

Kaur, J. (2013). Work-Life Balance: Its Correlation with Satisfaction with Life and Personality Dimensions Amongst College Teachers. International JournalOf Marketing, Financial Services \& Management Research. 2 (8): 24-35.

Keene, J.R., \& Quadagno, J. (2004). Predictors of Perceived Work-Family Balance: Gender Difference or Gender Similarity.Journal Sociological Perspectives, 47, 1-23.

Kelompok Study Wanita FISIP-UI (1990). Laporan Penelitian Para Ibu yang Berperan Tunggal dan yang Berperan Ganda. Jakarta: Lembaga Penerbit Fakultas Ekonomi Universitas Indonesia.

Kementrian Pertahanan Negara. (2016). Rapim Kemhan Tahun 2016 : Sistem Pertahanan Negara Dibangun Secara Terus Menerus. (Online). https:// www.kemhan.go.id/2016/01/12/rapimkemhan-tahun-2016-sistem-pertahanannegara-dibangun-secara-terusmenerus.html, diakses 6 November 2016.

Kirchmeyer, C. (2000). Work-life initiatives: Greed or Benevolence Regarding Workers Time. In C. L.Cooper \& D. M. Rousseau (Eds.),Trends in organizational behavior (Vol. 7, pp. 7993). West Sussex,UK: Wiley.

Kuswanthy, D. Herlina \& Probasari, Ninik. (2008). Peran Dukungan Organisasional dan Dukungan Suami dalam Memoderasi Pengaruh Tuntutan 
Waktu Peran Kerja terhadap Konflik Peran Ganda, Utilitas. Jurnal Manajemen \& Bisnis Vol. XVI NO.1; 15-25.

Laela, Chofitnah Rohmatul. (2015). Pengaruh Relation-Oriented Leadership Behavior terhadap Work-Life Balance pada Wanita Pekerja. Skripsi. Jurusan Psikologi Fakultas Ilmu Pendidikan Universitas Negeri Semarang.

Lazar, I., Osoian, C., \& Ratiu, P. (2010). The Role of Work Life Balance Practices in Order to Improve Organizational Performance. European Research Studies. Vol. XIII.

Linggawatie. (2014). Hubungan Work-Life Balance dan Retensi pada Karyawan Perempuan yang Sudah Berkeluarga. Skripsi. Universitas Katolik Widya Mandala Surabaya, Fakultas Psikologi.

Mariati (2013). Pengaruh Work-Life Balance Dan Burn Out Terhadap Kepuasan Kerja. Tesis. Yogyakarta: Universitas Atma Jaya Yogyakarta.

Markus,H.R.,\&Kitayama,S.

(1991).Cultureandtheself:Implicationsf orcognition,

emotion, andmotivation.PsychologicalR eview.98(2),224-53.DOI:10.1037/0033 $-295 X .98 .2 .224$

Maslichah, Nur I (2016). Pengaruh Work Life Balance dan Lingkungan Kerja Terhadap Kepuasan Kerja Karyawan (Studi pada Perawat RS Lavalette Malang Tahun 2016). Fakultas Ilmu Administrasi Universitas Brawijaya

Miles, MB Dan AM Huberman(1994). Qualitative Data Analysis: A Sourcebook Of New Methods. SAGE. Beverly Hills.

Mufidah (2004). Paradigma Gender. Malang: Bayumedia.

Nurendra, A.M (2016). Model Peranan Work Life Balance, Stres Kerja dan Kepuasan Kerja Pada Karyawan.
Indonesia Psychological Journal.

Novelia, P. (2013). Hubungan Antara WorkLife Balance Dan Komitmen Berorganisasi Pada Pegawai Perempuan. 1-44.

Nur Syahdi Katjasungkanah (2001). Potret Perempuan Tinjauan Politik Ekonomi dan Hukum Dizaman Ordebaru. Yogyakarta: Pustaka Pelajar.

Paloma \& Waridin. (2006). Analisis Work Life Balance dan Program Family Friendly terhadap Kepuasan Kerja: Studi Kasus Pada Rumah Sakit Panti Wilasa Citarum, Semarang $1-10$. Jurnal Benefit. Volume 10, No. 1.

Peter Worsley Et Al (1992). Pengantar Sosiologi Sebuah Pembanding. Yogyakarta. PT. Tiara Wacana.

Purba, S. D (2014). Effect of Work Life Balance \& Antecedent Variabel on Intention to Stay. (A Study Of Famale Employees In High Performance Bank In Jakarta). Internasional Journal Of Management \& Information Technology, 8(3).

Purwati Putrie. D (2016) Pengaruh Keseimbangan Kehidupan Kerja (Work -Life Balance) Terhadap Beban Kerja (Work Load) Divisi Penjualan di PT. ULAM TIBA HALIM (MARIMAS) CABANG SIDOARJO. Skripsi Psikologi, Fakultas Psikologi, Universitas Negri Islam Maulana Malik Ibrahim, Malang.

Putri. N, Dkk (2013). Hubungan Anatar Work-Life Balance dan Komitmen Berorganisasi pada Pegawai Perempuan. Jurnal Fakultas Psikologi, Universitas Indonesia

Rahayu, Angger Wiji. (2015). Perempuan Dan Belenggu Peran Kultural. Jurnal Perempuan( $\underline{\text { Http:// }}$ Www.Jurnalperempuan.Org/BlogFeminis-Muda/Perempuan-DanBelenggu-Peran-Kultural), Diakses 20 Oktober 2016 
Ramayulis, Et Al (1987). Pendidikan Islam Dalam Rumah Tangga. Jakarta: Kalam Mulia.

Risnawati. (2016). Peran ganda istri yang bekerja dalam membantu ekonomi keluarga buruh perkebunan kelapa sawit pada PT. Bumi Mas Argo di Kecamatan sandaran Kabupaten Kutai Timur. Ejurnal sosiatri-sosiologi. Vol. 4 (3).

Robbins, Stephen P. (2003). Perilaku organisasi. Jakarta : PT. Indeks Kelompok GRAMEDIA.

Santrock, J.W. 2002. Life-Span Development: Perkembangan Masa Hidup (edisi kelima). (Penerj. Achmad Chusairi, Juda Damanik; Ed. Herman Sinaga, Yati Sumiharti). Jakarta: Erlangga.

Saryono. (2011). Metodologi Penelitian Kualitatif Dalam Kesehatan. Yogyakarta: Nuha Medika. 